\title{
thebmj
}

Analysis

\section{International experience of paying for expensive medicines}

BMJ 2009; 338 doi: http://dx.doi.org/10.1136/bmj.b1993 (Published 29 May 2009) Cite this as: BMJ 2009;338:b1993

Monica Desai, academic clinical fellow public health, Ellen Nolte, senior lecturer, Nicholas Mays, professor of health policy, Athanasios Nikolentzos, research fellow

${ }^{1}$ Health Services Research Unit, London School of Hygiene, London WC1E 7HT

Correspondence to: E Nolte enolte@rand.org

- Accepted 6 May 2009

NHS patients in England are now allowed to pay for private treatment with drugs that are not funded by the NHS. But as Monica Desai and colleagues describe, it may not be easy to maintain a distinction between public and private care

The use of so called top-up payments for drugs that are not available on the National Health Service has caused controversy. Some people believe that it will result in increased access to medications1 while others warn that such payments contradict the founding principles of the NHS and may lead to greater inequalities. 2 Mike Richards's review Improving access to medicines for NHS patients and the government's response to the review have acknowledged that additional payments, which are already used in a non-uniform manner, must be accepted into practice.3 4 The review does, however, recognise that the right to pay for additional specialist care that is not funded by the NHS should be invoked rarely so as to minimise compromising the founding principle of the NHS - namely, to provide a comprehensive service to all on the basis of need, not ability to pay. 4

The Department of Health has set out a series of safeguards to ensure that patients opting to pay for additional private care do not lose their entitlement to NHS care while minimising the risk of public funds being used to subsidise private care. 3 We discuss some of the challenges posed by these new proposals and their implications for the NHS against the background of international experience.

\section{Background}

The Richards review attempts to conclude a longstanding controversy surrounding payment for high cost medicines in the NHS. In England, funding decisions for drugs are informed by the National Institute for Health and Clinical Excellence (NICE). Medicines recommended by NICE must be funded by primary care trusts (PCTs), the local purchasers of health services, to promote uniformity of access. However, for medicines not yet appraised or approved by NICE, individual PCTs decide on funding. They may fund the drugs through their service development budget or individual patients may apply to 
the PCT for exceptional funding if their condition is considered to have exceptional need for the drug in question.

PCTs receive an estimated 15000 requests for exceptional funding each year, with around a quarter relating to cancer drugs (box).4 Approval rates vary widely, but about two thirds of requests for cancer drugs and three quarters of requests for other treatments are accepted. There are no common procedures for decision making, and some drugs are funded by some PCTs but not others, making access a supposed "postcode lottery." 6 Differences in PCT decisions to fund medicines not yet appraised or approved by NICE have resulted in several court cases_for example, against a decision by West Sussex PCT not to fund lenalidomide for multiple myeloma.7

\section{Exceptional funding requests in England, 2006-8: evidence from selected audits}

102 applications for cancer treatments made by Christie Hospital, Manchester, were for six types of chemotherapy: cetuximab and bevacizumab (colorectal cancer); lenalidomide and rituximab (haematological malignancies); and sunitinib and sorafenib (renal cell carcinoma) 5

In an audit by the Rarer Cancers Forum most exceptional case applications were for drugs for very advanced cancer. The largest number of requests were for sunitinib, erlotinib, cetuximab, and bortezomib. 6 The audit did not report on the indications for which applications were made

Of applications made by Leeds Teaching Hospitals NHS Trust, two of the most common requests for non-cancer treatments were for ranibizumab for wet age related macular degeneration and monoclonal antibodies for inflammatory conditions related to rheumatoid arthritis or Crohn's disease 4

One other avenue for patients who wish to access these drugs is to agree to pay for them privately. However, until recently, standards of practice in England stipulated that a person could not top up their NHS care with additional private treatment. Specifically, a patient could not be both a private and an NHS patient for the treatment of the same condition during the same visit to an NHS organisation.8 Applying these standards led to few cases in which patients who chose to pay for unfunded treatments were then considered private patients and denied all of their NHS care for the specific condition.9

\section{Recommendations}

The Richards review clearly rejects top-ups within the NHS but has made provisions for patients who might wish to purchase additional drugs to receive these in a separate setting from their NHS care. Under this separate care option, any private care must be given in a separate private facility in parallel to NHS care. The aim is to maintain the entitlement to NHS care for those who opt to make additional payments, while ensuring that patients within the NHS are not disadvantaged.

Such provisions are recommended to be put in place against an overarching goal to minimise the number of patients who may want to top up their NHS care in the first place. To this effect, the review recommends continuing to put measures in place to improve the timeliness of NICE's technology appraisal process to ensure more timely decisions on new technologies; encouraging collaborative commissioning among PCTs for drugs not yet appraised or rejected by NICE, as has been done by the North of England Cancer Drug Approval Group 4 and the London Cancer New Drugs Group (www.lcndg.org.uk); and for drug companies to work with the Department of Health to promote greater 
flexibility on the pricing and availability of new drugs. In addition, NICE has recently introduced a higher cost effectiveness threshold for treatments aimed at extending the life of terminally ill patients.10

\section{Implications for the NHS}

The separate care model proposed by the Richards review is similar to existing practice in some places in the NHS. For example, organisations use "episodes of care" to separate NHS and private treatment, permitting private payment for a single visit while maintaining the patient's entitlement to NHS care. This approach was initially used for elective surgery, where treatment is generally time limited and specific.

However, defining separate care is more difficult for complex conditions, several of which involve drugs that account for a considerable proportion of exceptional treatment requests4-for example,

monoclonal antibodies to treat rheumatoid arthritis. Treatment of such conditions requires several visits and close follow-up because of the potential side effects and complications of many of these drugs, which are often new and may not have been evaluated in phase III trials.

The Richards review acknowledged that there is a risk that the NHS may have to cover some of the costs of complications resulting from the use of unfunded drugs. The Department of Health's guidance seeks to clarify the boundaries between what should be publicly and privately paid for. Using the example of an unfunded cancer drug, it notes that, in addition to the cost of the drug itself, the patient should have to cover the costs of any staff who administer the drug and any related tests needed as a result of taking the unfunded drug. Non-emergency complications resulting from the drug treatment should also be paid for privately, although the NHS "should never refuse to treat patients simply because the cause of the complications is unclear," 3 suggesting that, in practice, the distinction between what is publicly and what is privately funded cannot be made on clear predetermined grounds.11

\section{International experience}

Experience in other countries that have used the principle of separate care shows that the distinction can indeed become blurred.12 Canada, for example, has a universal health system with single payer schemes in each province that cover drugs for inpatient care. However, access to outpatient prescription drugs is through a mix of public and private insurance and access to certain drugs, such as cancer drugs, varies between provinces.13 In Ontario, patients are able to pay for cancer drugs that are not funded, but these cannot be administered in public hospitals.14 Unfunded cancer drugs initially had to be administered in a private clinic. However, there was concern about safety, with, for example, some patients approaching untrained staff in primary care to receive them.15 Other safety issues related to the implications of having to give several drugs that should be received simultaneously but only one of which was paid for by the patient and loss of continuity of care, with care for the same disease process being provided by different clinicians. A provincial working group was set up to provide clarification and to ensure patient safety without compromising the public health system. As a result, some patients are now beginning to have unfunded drugs administered at Ontario public hospitals under the care of their oncologists, but for private payment, so blurring the initially clear separation between private and public care.

New Zealand, which also has a universal tax funded system, allows patients to pay for drugs that are not publicly funded only in a private setting. The only exception to this is if there is a direct benefit to publicly funded patients, such as an improvement in clinical quality or efficiency of a service. However, this distinction has become more blurred with the increase in the number of high cost drugs. There has 
been pressure to allow certain unfunded cancer drugs to be administered in public facilities, especially in regions that have a shortage of private facilities. The Ministry of Health is considering allowing this to occur under certain limited conditions, such as when there are no resource implications for the public sector, the treatment is time limited, and there is a probability of a positive response to the drug that may offset costs of alternative management.

Elsewhere, the approach to topping-up under the statutory system varies widely.12 In countries such as Australia, Italy, and Spain, patients who purchase an unfunded (licensed) drug can remain under the statutory system for the treatment of that condition if the drug was prescribed by the treating practitioner. In Australia, the prescribing doctor takes clinical responsibility for the treatment of that patient. In Spain and Italy the national health service takes clinical and financial responsibility for supervising the administration of the unfunded drug and for monitoring any side effects.

In contrast, Norway and Sweden have attempted to minimise mixing public and private health care. In Norway, cancer patients may choose to receive treatment abroad, where alternative treatments may be purchased privately.12 Those patients will have to cover the entire costs of the treatment themselves. In Sweden, patients can buy licensed drugs (mainly as outpatients) that are not part of the pharmaceutical reimbursement scheme and have them administered by private providers, although such cases are few.

\section{Questions remaining}

The international experience shows that there are no easy solutions to balancing access to treatments outside the publicly funded system with the principle of equal treatment within the public system, and that it is difficult to prevent a blurring between public and private financing and provision. The Richards review is a well considered effort to resolve a set of difficult trade-offs between conflicting policy imperatives. But the risk remains that the introduction of additional payments may herald the start of overt integration of publicly and privately financed health care with implications for equity.

Several of the drugs that will be available under the policy of additional payments are expensive, particularly cancer drugs and those that require multiple cycles of treatment. Thus top-up insurance policies have already been marketed,16 and transparent procedures need to be put in place to ensure that patients are protected not only from large additional payments but also from potential exploitation by insurance companies and drug manufacturers.

The Richards review and the Department of Health's guidance emphasise the importance of training clinicians to ensure that they are not only aware of the options available to their patients but are able to have an informed conversation with patients when advising them on the costs and benefits of making additional payments. 34 Patients vary in their preferences for care and the importance they place on different health outcomes, and among patients with advanced cancer there is substantial variation in attitudes towards intensive treatment for improved survival and willingness to trade greater toxicity of treatment for improved quality of life.17 18 Recent work from the United States shows how informed end of life conversations between clinicians and patients can improve patients' quality of life in the final weeks of life as well as lower healthcare costs because of more limited use of intensive interventions.19 There is thus a need to train healthcare professionals so that they can take patients through their options in an informed manner.

The Department of Health's guidance seeks to clarify the scope of additional payments, stipulating that patients will have to meet any additional costs that may be associated with the private treatment, such 
as management of side effects. 3 It also provides guidance on choice of treatment settings to ensure maximal safety for patients who opt to use additional payments-for example, allowing exemption from the principle of separation if patient safety would otherwise be put at risk. However, these provisos highlight that the distinction between public and privately funded care in the NHS risks becoming increasingly distorted. NHS providers will need to ensure robust clinical governance measures to minimise blurring and steps to prevent conflicts of interest; they also need to ensure that NHS resources are not reduced as patients make additional private payments. Ensuring that the NHS provides a comprehensive service to all on the basis of need not ability to pay, as recently reaffirmed in the NHS constitution, 20 will continue to present a policy and practice challenge.

\section{Notes}

Cite this as: BMJ 2009;338:b1993

\section{Footnotes}

- We thank Karen Bloor and Carolyn Tuohy for helpful comments on an earlier draft.

- Contributors and sources: This paper arose from a review by AN, EN, and NM for the Richards review as part of the project "An 'on-call' facility for international healthcare comparisons." MD and EN conceived and drafted the paper; all authors contributed to revising the paper critically for structure and important intellectual content, as well as approving the final version. EN is the guarantor.

- Funding: The On-call Facility for International Healthcare Comparisons is funded by the Department of Health in England through its policy research programme (grant No 0510002). EN is funded by a career scientist award from the National Institute for Health Research. The Department of Health does not accept any responsibility for the views expressed.

- Competing interests: None declared.

- Provenance and peer review: Not commissioned; externally peer reviewed.

\section{References}

1. Gubb J. Should patients be able to pay top-up fees to receive the treatment they want? Yes. BMJ2008;336:1104.

2. Bloor K. Should patients be able to pay top-up fees to receive the treatment they want? No. BMJ2008;336:1105.

3. Department of Health. Guidance on NHS patients who wish to pay for additional private care. London: DoH, 2009.

4. Richards M. Improving access to medicines for NHS patients. London: Department of Health, 2008.

5. Clarke R, Waddell T, Gallagher J, Lee K, Radhakrishna G, Cavet J, et al. A postcode lottery still exists for cancer patients with exceptional circumstances. Clin Oncol2008;20:771-2.

6. Rarer Cancers Forum. Taking exception: an audit of the policies and processes used by PCTs to determine exceptional funding requests. Canterbury: Rarer Cancers Forum, 2008.

7. R (Ross) v West Sussex PCT. [2008] EWHC 2252 (Admin) September 10, 2008. 
8. Department of Health. A code of conduct for private practice. Recommended standards of practice for NHS consultants. London: DoH, 2004.

9. Templeton S. NHS scandal: dying cancer victim was forced to pay. Sunday Times2008 June 1. www.timesonline.co.uk/tol/life and style/health/article4040146.ece.

10. National Institute for Health and Clinical Excellence. Appraising life-extending, end of life treatments. www.nice.org.uk/media/88A/F2/SupplementaryAdviceTACEoL.pdf.

11. Appleby J, Maybin J. Topping up NHS care. BMJ2008;337:1122-3.

12. Nikolentzos A, Nolte E, Mays N. Paying for (expensive) drugs in the statutory system: an overview of experiences in 13 countries.

www.dh.gov.uk/en/Publicationsandstatistics/Publications/PublicationsPolicyAndGuidance/DH 089990.

13. Khoo K, Colucci R, Hryniuk W, Ragaz J, Sehdev S, Savage C. The new wave of cancer drugs. Report Card on Cancer in Canada2007;10:40-52.

14. Provincial Working Group. Report of the Provincial Working Group on the delivery of oncology medications for private payments in Ontario hospitals. Toronto: PWG, 2006.

15. Flood C, Hardcastle L. The private sale of cancer drugs in Ontario's public hospitals: tough issues at the public/private interface in health care. McGill Health Law Publ 2007;1:7-21.

16. Satchell G. Insurers eye NHS top ups market. BBC News2008 Dec 23. http://news.bbc.co.uk/1/hi/health/7669230.stm.

17. Chu D, Kim S, Kuo H, Ozacar R, Salajka F, Krishnamurthy S, et al. Patient attitudes towards chemotherapy as assessed by patient versus physician: a prospective observational study in advanced non-small cell lung cancer. Lung Cancer2007;56:433-43.

18. Silvestri G, Pritchard R, Welch H. Preferences for chemotherapy in patients with advanced non-small cell lung cancer: descriptive study based on scripted interviews. BMJ1998;317:771-5.

19. Zhang B, Wright A, Huskamp H, Nilsson M, Maciejewski M, Earle $\mathrm{C}$, et al. Health care costs in the last week of life. JAMA2009;169:480-8.

20. Department of Health. The NHS constitution for England. London: DoH, 2009. 